\title{
The dual role and therapeutic potential of high-mobility group box 1 in cancer
}

\author{
Si-Jia $\mathrm{He}^{1,2}$, Jin Cheng ${ }^{1,2}$, Xiao Feng ${ }^{1,2}$, Yang $\mathbf{Y u}^{3}$, Ling Tian ${ }^{1,2,4}$ and Qian Huang ${ }^{1,2}$ \\ ${ }^{1}$ Cancer Center, Shanghai General Hospital, Shanghai Jiao Tong University School of Medicine, Shanghai, China \\ ${ }^{2}$ Shanghai Key Laboratory of Pancreatic Diseases, Shanghai General Hospital, Shanghai Jiao Tong University School of \\ Medicine, Shanghai, China \\ ${ }^{3}$ Oncology Department, Henan Provincial People's Hospital, Zhengzhou, China \\ ${ }^{4}$ Institute of Translational Medicine, Shanghai General Hospital, Shanghai Jiao Tong University School of Medicine, Shanghai, \\ China
}

Correspondence to: Qian Huang, email: Qhuang@sjtu.edu.cn

Keywords: HMGBI, RAGE, TLRs, cancer, anticancer therapy

Received: September 26, $2016 \quad$ Accepted: April 24, $2017 \quad$ Published: May 16, 2017

Copyright: He et al. This is an open-access article distributed under the terms of the Creative Commons Attribution License 3.0 (CC BY 3.0), which permits unrestricted use, distribution, and reproduction in any medium, provided the original author and source are credited.

\section{ABSTRACT}

High-mobility group box 1 (HMGB1) is an abundant protein in most eukaryocytes. It can bind to several receptors such as advanced glycation end products (RAGE) and Toll-like receptors (TLRs), in direct or indirect way. The biological effects of HMGB1 depend on its expression and subcellular location. Inside the nucleus, HMGB1 is engaged in many DNA events such as DNA repair, transcription, telomere maintenance, and genome stability. While outside the nucleus, it possesses more complicated functions, including regulating cell proliferation, autophagy, inflammation and immunity. During tumor development, HMGB1 has been characterized as both a pro- and anti-tumoral protein by either promoting or suppressing tumor growth, proliferation, angiogenesis, invasion and metastasis. However, the current knowledge concerning the positive and negative effects of HMGB1 on tumor development is not explicit. Here, we evaluate the role of HMGB1 in tumor development and attempt to reconcile the dual effects of HMGB1 in carcinogenesis. Furthermore, we would like to present current strategies targeting against HMGB1, its receptor or release, which have shown potentially therapeutic value in cancer intervention.

\section{INTRODUCTION}

High-mobility group box 1 protein (HMGB1), also known as amphoterin or HMG1, is an evolutionarily conserved non-histone DNA-binding protein and named for its high electrophoretic mobility on polyacrylamide gels. It was first identified as a group of chromatinassociated protein with high acidic and basic amino acid contents in 1973 [1]. HMGB1 is widely expressed in most mammalian cells, except those erythrocytes and cornifying epithelial cells that have eliminated nucleus. Nuclear HMGB1 is engaged in many DNA activities, such as DNA stability, repair, transcription and recombination. While in extracellular space, HMGB1 plays a more complicated role. It acts as the prototypic damage-associated molecular pattern molecule (DAMP) and interacts with several receptors including the receptor for advanced glycation end products (RAGE), Toll-like receptors (TLRs) and others for diverse biological functions. Since its discovery, HMGB1 has been implicated in many disease states including inflammation, immune disorders and cancer. In cancer, the dysfunction of HMGB1 has been verified to be associated with all the central hallmarks of cancer [2]. This review is focused on the current knowledge of HMGB1 biological features, especially in relation to the development of cancer and its potential therapeutic values. 


\section{THE BIOLOGY OF HMGB1}

\section{Structure}

The high-mobility group box (HMGB) protein family is a group of highly conserved protein family that contains HMG box domains. HMG box is a novel type of DNA binding motif that is characterized by three $\alpha$-helices arranged in an L-shaped configuration [3]. There are four members in this group: HMGB1, HMGB2, HMGB3 and HMGB4. HMGB1, encoded on human chromosome $13 q 12-13$, is a relatively small protein with three distinct domains: two tandem HMG box domains (A box and B box) and an acidic $\mathrm{C}$-terminal tail, containing a stretch of approximately 30 continuous glutamic and aspartic acid residues [3] (Figure 1). Functionally, the A (1-79 amino acid) and B (89-162 amino acid) boxes can interact with DNA to bend or distort the double helix [4]. The B box recapitulates the cytokine activity of full length HMGB1 and efficiently induces macrophage secretion of additional pro-inflammatory cytokines [5]. This cytokine activity can be antagonized by recombinant A box [6]. Residues 150183 are responsible for binding with receptor for advanced glycation end products (RAGE), whereas residues 89-108 are responsible for binding with Toll-like receptors (TLRs) [4]. The C-terminal tail (186-215 amino acid) contributes to the spatial arrangement of both $\mathrm{A}$ and $\mathrm{B}$ boxes and modulates HMGB1 DNA-binding specificity [7]. It folds back to the N-terminal part of HMGB1, serving as a lid to cover the DNA binding domains, which only allows the DNA with special structure to assess the DNA binding domains [8]. This feature makes HMGB1 not occupied by linear DNAs in the nucleus [8]. Removal of the C-tail from HMGB1 enhances its DNA-binding activity, but weakens its preference for bended DNAs over linear DNAs [8]. Importantly, there are three redox-sensitive cysteine residues at positions 23,45 , and 106 , which are highly conserved across all the species [4]. Cysteine 23 and cysteine 45 are located within the A box and can form an intramolecular disulfide bond in response to oxidative stress, which is required for binding to Beclin1 and sustaining autophagy [9]. However, cysteine 106, which is unpaired and located within the B box, appears to be critical for the nucleocytoplasmic shuttling of HMGB1 $[2,10]$.

\section{Receptor}

There are receptors that directly bind to HMGB1, such as RAGE, TLR2, TLR4 and TIM3. However, there are several receptors associated with HMGB1, including TLR9, CXCR4. All these receptors with or without direct binding to HMGB1 exert diverse pathological and physiological functions.

\section{RAGE}

Receptor for advanced glycation end products (RAGE) is a transmembrane receptor encoded by gene on chromosome 6p21.3. The extracellular domain of RAGE, which is used for ligand binding, contains one variablelike (V) and two constant-like (C) type domains. The V domain has two $\mathrm{N}$-glycosylation sites and is responsible for extracellular ligand binding. The 43-amino acid cytoplasmic tail of RAGE is required for intracellular signaling transduction. RAGE has several isoforms deriving from alternative splicing including full-length (flRAGE), membrane-bound (mRAGE) and various soluble forms lacking the transmembrane domain [11]. Soluble RAGE can be generated through proteolytic cleavage of mRAGE by the sheddase called a disintegrin and metalloprotease 10 (ADAM10). The sheddase ADAM10 is a membrane protease, which promotes RAGE shedding via binding its ligand HMGB1 [12]. RAGE is now known as a multi-ligand receptor and binds to a number of ligands such as advanced glycation end products (AGE), HMGB1, $\beta$-amyloid fibrils, certain S100 proteins, DNA, RNA and other molecules, adjusting a series of physiological activities and pathological processes [13, 14]. A great number of studies demonstrate that RAGE is indispensable for HMGB1-induced cell proliferation, regeneration, migration, inflammation, autophagy and immunity [14-16]. Knockdown of RAGE by specific siRNA or RAGE ligand application increased cancer cell proliferation [15]. Knockout of RAGE decreases tumor growth and metastasis, increases chemotherapy resistance both in vitro and in vivo [17]. It is demonstrated that the HMGB1-RAGE signaling axis contributes to cell proliferation and metastasis by inducing nuclear factor $\kappa \mathrm{B}(\mathrm{NF}-\kappa \mathrm{B})$ activation, revealing HMGB1-RAGE as a potential target for therapeutic intervention in cancer [18].

\section{TLRs}

The Toll-like receptors (TLRs) are a family of transmembrane receptors that contain extracellular leucine-rich repeats (LRRs) and a cytoplasmic Toll/ interleukin-1 receptor (TIR) domain. The LRRs are used for ligand binding and trigger signal transduction pathways through TIR domains with conserved adaptor molecules [19]. There are five adaptor molecules that link TLRs to downstream kinases: myeloid differentiation primary response gene 88 (MyD88), TIR domaincontaining adaptor protein (TIRAP, also known as $\mathrm{Mal})$, TIR domain-containing adaptor protein inducing IFN- $\beta$ (TRIF, also known as TICAM1), TRIF-related adaptor molecule (TRAM, also known as TICAM2) and sterile $\alpha$ and HEAT-Armadillo motifs (SARM) [20]. Most TLRs signal utilizes MyD88, except that TLR3 signal merely utilizes TRIF. TLR4 is the only receptor that transduces signals through MyD88 and TRIF. TLR signaling pathways are broadly classified as the MyD88dependent and MyD88-independent pathways. After binding with individual ligands, TLRs recruit MyD88 or other adaptor molecules, leading to multiple activation of downstream factors, such as NF- $\mathrm{kB}$, mitogen-associated protein kinase (MAPK), and interferon (IFN) regulatory 
factors [19]. TLRs are mainly expressed in innate immune cells, inducing and regulating adaptive immune responses. However, TLRs are also expressed on other cell types, including endothelial, epithelial and tumor cells. Modulation of TLR signaling can confer anti- or protumor effects, which depends on the TLR, cancer subtype and the tumor-infiltrating immune cells [21]. The antitumor effects can be achieved by inducing direct tumor cell death or improving anti-tumor immune responses, and the pro-tumor effects can result from activating tumor cell survival and proliferation signaling pathways or suppressing inflammatory immune cells in the tumor microenvironment [21]. TLRs are pattern recognition receptors (PRRs) that recognize a wide range of pathogenassociated molecular patterns (PAMPs) and endogenous damage-associated molecular patterns (DAMPs). As such, HMGB1 can interact with TLRs and then activate relevant signal transduction pathways to produce a series of cytokines and chemokines. It is demonstrated that irradiated tumor cells released HMGB1 can activate TLR4 on dendritic cells and lead to tumor elimination by tumor-specific $\mathrm{T}$ cells [22]. Knockout of TLR4 decreases HMGB1-induced tissue injury, cell migration and adhesion, angiogenesis, inflammation and immunity responses [22, 23]. In addition, TLR2 is connected with tissue injury, cell migration and adhesion, inflammation, and stem cell self-renewal [24]. TLR9 is initially localized in the endoplasmic reticulum (ER), and redistributes to early endosomes upon stimulation with $\mathrm{CpG}$-DNA via an HMGB1-dependent way [25]. Inhibition of both TLR9 and HMGB1 suppresses inflammatory cytokine secretion and confers protection from liver ischemia-reperfusion injury [26].

\section{TIM3}

T cell immunoglobulin domain and mucin domain-3 (TIM3) is a member of the TIM family consisting of an $\mathrm{N}$-terminal immunoglobulin variable (IgV) domain followed by a mucin domain, a transmembrane domain and a cytoplasmic tail [27]. TIM3 is located on human chromosome 5q33.2 [28] and expressed on dendritic cells (DCs), monocytes, macrophages, and natural kill (NK) cells [29]. It is a marker for NK-cell activation or maturation and can suppress NK cell-mediated cytotoxicity when crosslinked [30]. The interaction between galectin9 and TIM3 can induce apoptosis in T cells [30]. DC-derived TIM3

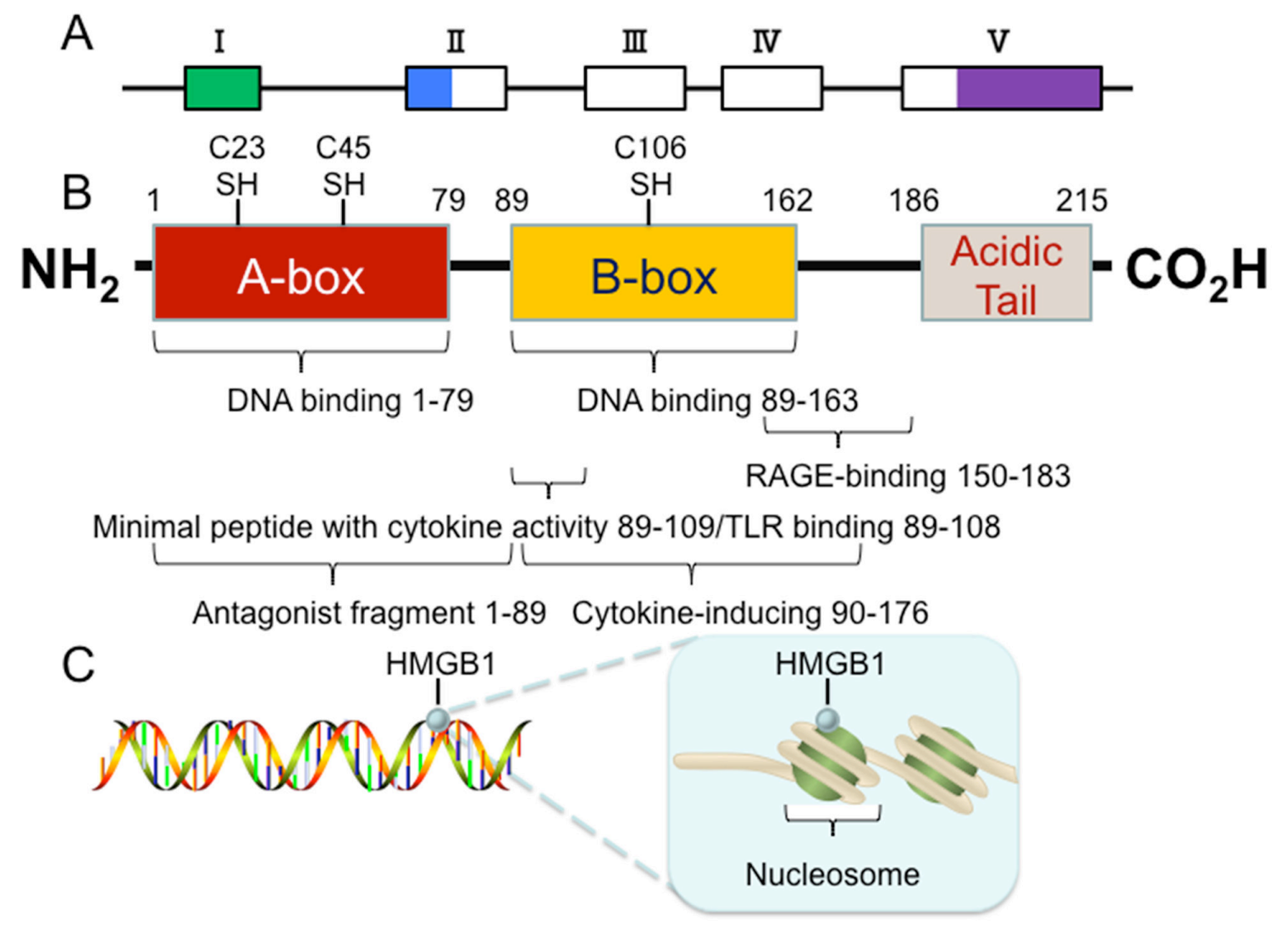

Figure 1: Structure of the HMGB1 protein. (A) The 5 exons of human HMGB1 gene are indicated by boxes (hollow for translated regions and solid for un-translated regions). (B) The human HMGB1 protein has 215 amino acid residues and is composed of three domains: A box, B box and an acidic C-terminal tail. There are three redox-sensitive cysteine residues at positions 23, 45, and 106, which regulate HMGB1 function in response to oxidative stress. (C) The human HMGB1 is loosely and transiently associated with nucleosomes. In this location, HMGB1 is important for spatial segregation and nuclear homeostasis. 
Table 1: A summary of data on HMGB1 expression and localization in normal and tumor tissue

\begin{tabular}{|c|c|c|c|c|c|c|}
\hline Tissue & HMGB1 level & Subcellular location & Tumor & HMGB1 level & $\begin{array}{l}\text { Subcellular } \\
\text { location }\end{array}$ & Reference \\
\hline Liver & Low & $\mathrm{C}$ & $\begin{array}{l}\text { Hepatocellular } \\
\text { carcinoma }\end{array}$ & High & $\mathrm{N}, \mathrm{C}$ & {$[130]$} \\
\hline Stomach & Low & nd & Gastric carcinoma & High & $\mathrm{N}$ & [131] \\
\hline Colon & Low & nd & Colorectal carcinoma & High & $\mathrm{N}, \mathrm{C} \mathrm{N}$ & [132] \\
\hline Pancreas & Low & nd & Pancreatic carcinoma & High & $\mathrm{N}, \mathrm{C}$ & [133] \\
\hline Breast & Low & nd & Breast cancer & High & $\mathrm{N}, \mathrm{C}$ & [134] \\
\hline Cervix & Low & nd & Cervical carcinoma & High & $\mathrm{N}, \mathrm{C}$ & [135] \\
\hline Brain & $\begin{array}{l}\text { Undetectable } \\
\text { in most cells } \\
\text { in adult } \\
\text { mouse brain, } \\
\text { present during } \\
\text { development }\end{array}$ & $\mathrm{C}$ & Glioma & High & $\mathrm{C}, \mathrm{N}$ & {$[136]$} \\
\hline Thymus & $\begin{array}{l}\text { High in young } \\
\text { rats, low in old } \\
\text { rats }\end{array}$ & $\mathrm{N}, \mathrm{C}$ & $\begin{array}{c}\text { Thymic epithelial } \\
\text { tumors }\end{array}$ & High & $\mathrm{N}, \mathrm{C}$ & {$[137]$} \\
\hline $\begin{array}{l}\text { Lymphoid } \\
\text { tissues }\end{array}$ & Low & $\mathrm{N}, \mathrm{C}$ & $\begin{array}{l}\text { Non-Hodgkin } \\
\text { lymphoma }\end{array}$ & High & $\mathrm{N}$ & [138] \\
\hline
\end{tabular}

$\mathrm{N}$ : nuclear localization; C: cytoplasmic localization; nd: not determined.

can interact with HMGB1 and suppress the recruitment of nucleic acids to endosomes, which attenuates the antitumor efficacy of DNA vaccines and chemotherapy [31]. Blockade of TIM3 improves antitumor efficacy of anticancer cytotoxic agents by augmenting HMGB1mediated nucleic acid-sensing systems [29, 30]. As TIM3 also serves as a receptor for phosphatidylserine (PtdSer) for the engulfment of apoptotic cells, blockade of TIM3 impairs the phagocytotic capacity of DCs, thus impeding the recognition of dying tumor cells [31].

\section{CXCR4}

$\mathrm{C}-\mathrm{X}-\mathrm{C}$ chemokine receptor type 4 (CXCR4) is a member of the $G$ protein-coupled seven-transmembrane receptors (GPCRs), which is expressed lower in normal tissues but significantly higher in tumor tissues. CXCR 4 overexpression in tumor tissue has been correlated to tumor aggressiveness, high risk of metastasis and recurrence [32]. CXCR4 is well known to be a coreceptor for $\mathrm{CD} 4^{<\sup >+<\text { sup }>} \mathrm{T}$-cell infection of human immunodeficiency virus (HIV) type 1 [33]. Chemokine stromal cell-derived factor-1 (SDF-1, also known as CXC chemokine ligand 12) is a ligand of CXCR4. The attraction between CXCR4 and SDF-1 promotes cell migration and invasion by activation of RAS/MAPKs, JAK/STAT and AKT/PI3K [34, 35]. Recent evidence demonstrates that the heterocomplex formed by HMGB1 and CXCL12 can bind to CXCR4 and promote recruitment of inflammatory cells to damaged tissues [36]. NF- $\kappa \mathrm{B}$ signaling pathway is critical to sustain CXCL12/SDF-1 production for cells to migrate toward HMGB1, indicating that HMGB1mediated cell migration is regulated through NF- $\kappa B$ signaling pathway [37].

\section{Expression and subcellular location}

In general, HMGB1 is ubiquitously expressed to a very high level, which is believed to be only 10 times less than core histones. However, HMGB1 expression and subcellular localization varies depending on cell types, tissues and developmentally regulated to cues from the environment (Table 1) [38].

The expression of HMGB1 is high in both nuclei and cytoplasm of lymphoid tissues and testis, whilst low in cytoplasm of hepatic tissues and brain, mainly in the cytosol [39]. In mouse testis, HMGB1 appears to be expressed in spermatogonia, lower in spermatocytes, and absent in spermatids [38]. Immunohistochemistry of human arteries shows that HMGB1 is abundant in the nuclei of endothelial cells, but scarce in vascular smooth muscle cells [40]. The expression levels of HMGB1 also vary with age in rats, which is higher in the thymus of younger rats than the older rats [41]. The expression level of HMGB1 is associated with the differentiation stage of cells as well. Basically, HMGB1 expression is low in differentiated cells but high in undifferentiated 
cells [39]. The expression of HMGB1 in myeloid cells is higher than in lymphoid cells [42]. HMGB1 is highly expressed in most tumor types. Previous studies found that the expression of HMGB1 was much higher in tumor than in the normal tissue counterpart, such as hepatocellular carcinoma [15], breast carcinomas [43] and colorectal adenocarcinomas [44]. However, certain cancers such as adrenal gland carcinoma contain no HMGB1 protein [38].

Although HMGB1 is a nuclear protein, it can be transited and influenced by several posttranslational modifications such as acetylation, phosphorylation, methylation and oxidation. These modifications modulate HMGB1 structure, localization and subsequent biological functions [2], which will be discussed later.

\section{Release}

\section{Active release}

HMGB1 is a kind of 'leaderless' cytokine, which means it is not directly translocated from the Golgi apparatus to the cell surface. It requires access to be secreted in organelles that belong to the endolysosomal compartment [45]. The active release of HMGB1 initiates when extracellular molecules interact with cell membrane receptor or hypoxia occurs slowly. Many cell types can actively release HMGB1, such as monocytes, macrophages, DCs, NK cells, endothelial cells and tumor cells [46] (Figure 2). However, the mechanisms of this secretion may have discrepancies between different cell types. Monocytes have been the most deeply researched cell type in relation to secretion of HMGB1 so far. In monocytes, HMGB1 have to relocate from the nucleus to cytoplasmic secretory lysosomes or organelles, and then it can be released out of the cells, which is similar with the secretion of IL-1 $\beta$. When monocytes activated by LPS, TNF, IL-1 or IFN- $\gamma$, HMGB1 will release out of the nucleus and accumulate in the cytoplasm. The cytoplasm HMGB1 is acetylated and phosphorylated so that it is forbidden to get into nuclear compartment again. Then the cytoplasmic HMGB1 is enveloped into secretory lysosomes and fuses with the cell membrane. The release of HMGB1 on cytoplasmic organelles is initiated by lysophosphatidylcholine [16]. Recently some studies have indicated that sublethal cellular hypoxia induces active HMGB1 release rather than passive release in a cell type-independent way. In synovitis, hypoxic areas were found to be coincided with areas of maximal pathological HMGB1 expression, which substantiated the connection between ischemia and HMGB1 translocation [26].

\section{A}

\section{Passive release}

\section{B}

\section{Active release}
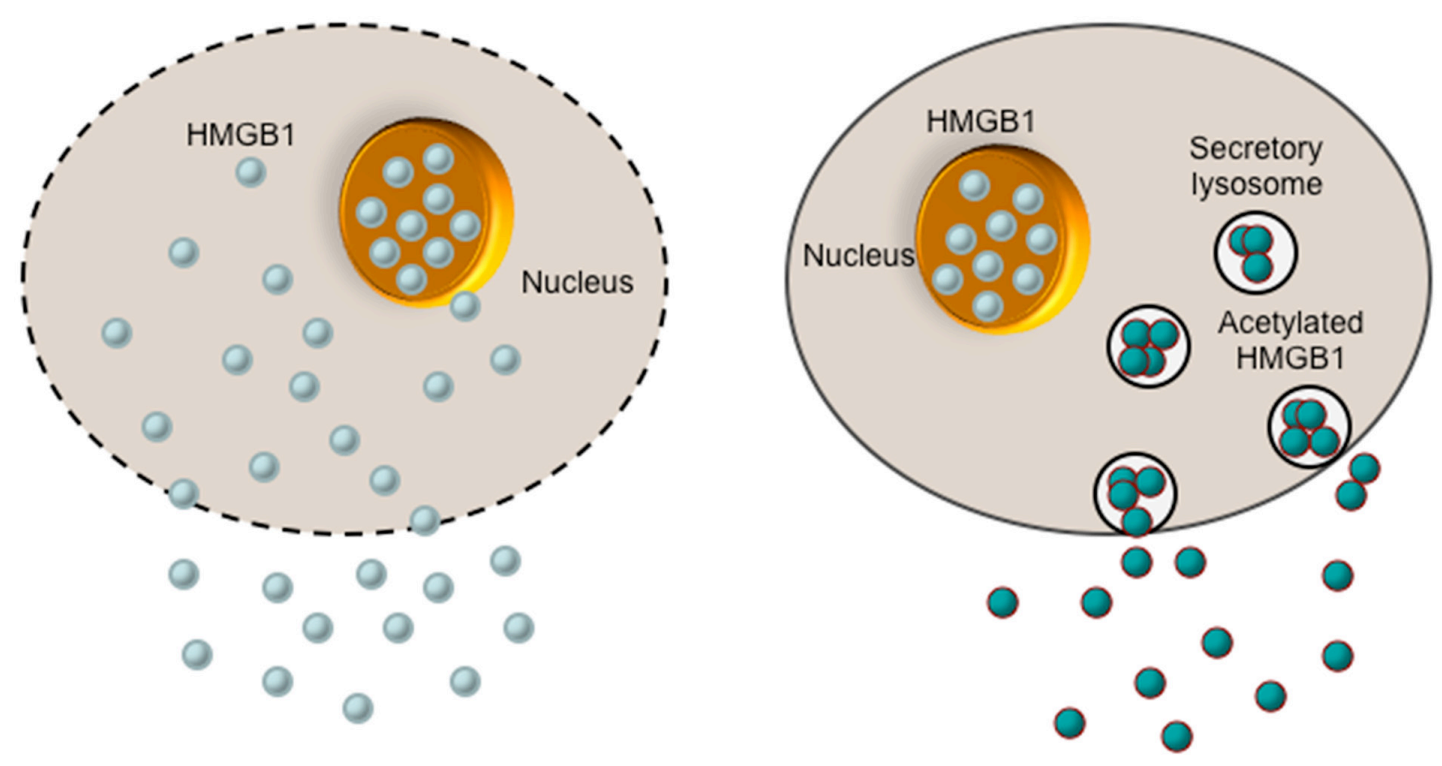

Figure 2: Release of the HMGB1 protein. There are two mechanisms of cells to release HMGB1 into the extracellular environment (passive release vs. active release). (A) HMGB1 is passively released into extracellular space from damaged cells or necrotic cells with leaky plasma membranes. Apoptotic cells that undergo secondary necrosis can also motivate late HMGB1 release. (B) HMGB1 can be actively released from activated cells such as inflammatory cells and immune cells. In this process, HMGB1 is acetylated, which prevents it from getting back to nucleus. Then the cytoplasmic HMGB1 is enveloped into secretory lysosomes, fuses with the cell membrane, and finally released into the environment. 


\section{Passive release}

The bond between HMGB1 and chromatin is loose, except that in granulocytes HMGB1 is tightly sequestered in an insoluble form. Thus, HMGB1 can be passively released into the extracellular space when the cells come through necrotic process (Figure 2). It should be noted that, in apoptotic cells, this does not occur, presumably on account that HMGB1 attaches to cruciform DNA or hypoacetylated proteins within apoptotic-cell nucleus [45]. However, apoptotic cells that may undergo secondary necrosis, motivating late HMGB1 release [46-48]. In mice rheumatoid arthritis model, HMGB1 can be secreted via necrotic macrophages and leaky apoptotic cells [47]. Furthermore, many of the macrophages that overtake undigested apoptotic bodies, get activated before cell death and actively secrete TNF, IL-1 $\beta$, and possibly HMGB1 [46].

\section{THE FUNCTION OF HMGB1 IN CANCER}

\section{Nuclear function of HMGB1}

\section{DNA chaperone}

Nuclear HMGB1 acts as a DNA chaperone that binds to DNA structure without sequence-specificity (Figure 3).
The flanking sequences of $\mathrm{A}$ box and $\mathrm{B}$ box as well as the acidic $\mathrm{C}$ terminal have the ability to regulate their DNA binding activities [49]. The binding between HMGB1 and DNA is enhanced when A box and B box are covalently connected. Post-translational modifications also regulate HMGB1 binding to DNA $[50,51]$. For example, methylation of HMGB1 weakens its DNA binding activity by altering its conformation [52]. In addition, HMGB1 has a relatively high affinity to noncanonical DNA structures such as singlestranded DNA, synthetic cruciform structures, supercoiled DNA molecules and Z-DNA, preferentially DNA minicircles, four-way junctions, looped structures and hemicatenated DNA $[49,53]$. Nuclear HMGB1 can also bend and change DNA conformation. HMGB1 binds to nucleosomes at the dyad axis and promotes nucleosome sliding, and bends to DNA to make chromatin more accessible [54]. The DNA bending activity of HMGB1 is maintained with HMG boxes [55]. The B box has "primary" intercalating Phe102 and "secondary" intercalating lle121, while the A box only has "secondary" intercalating Phe37. Thus, the B box contributes more to DNA bending. Mutation of these three intercalating residues prevent HMGB1 bind to chromatin and impair the ability of HMGB1 to bend DNA [49]. Generally, nuclear HMGB1 is identified as an "architectural" factor to facilitate the assembly of certain nucleoprotein complexes and

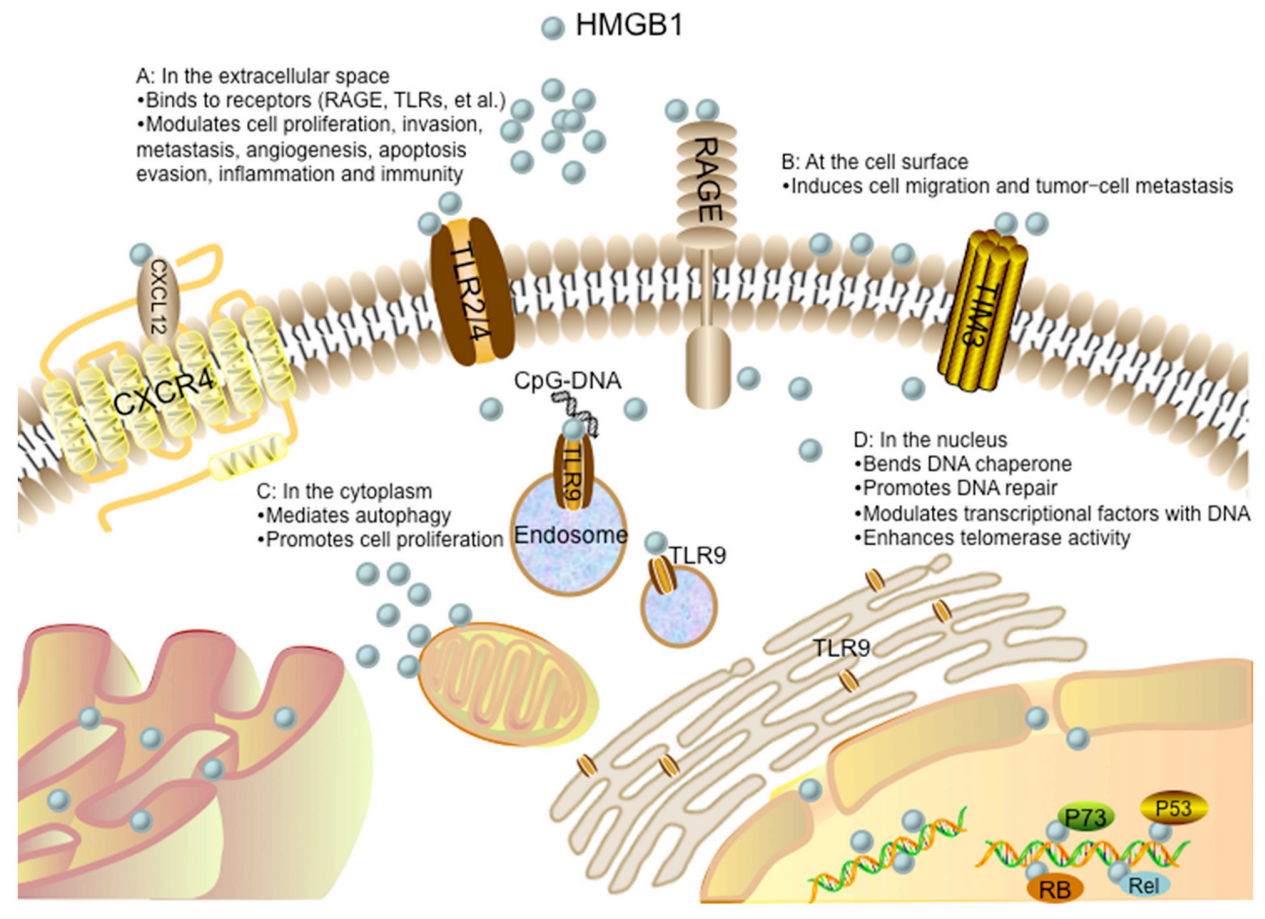

Figure 3: Role of the HMGB1 protein in cancer progression. (A) In the extracellular space, HMGB1 signals through receptors (such as RAGE, TLRs, TIM3, and CXCR4), driving cell proliferation, invasion, metastasis, angiogenesis, apoptosis evasion, inflammation and immunity. The interaction between HMGB1 and CXCR4 is dependent on CXCL12. TLR9 is initially localized in the endoplasmic reticulum (ER), and redistributes to early endosomes upon stimulation with CpG-DNA via an HMGB1-dependent way. (B) HMGB1 present at the cell surface promotes cell migration and tumor-cell metastasis. (C) In the cytoplasm, HMGB1 regulates autophagy and promotes cell proliferation. (D) In the nucleus, HMGB1 acts as a DNA chaperone participating in DNA repair and transcription. HMGB1 can also interact with transcription factors and enhance their activities such as p53, p73, members of the Rel/NFkB family and RB. Nuclear HMGB1 enhances telomerase activity and modulates telomere homeostasis. 
participate in fundamental events such as DNA replication, remodeling and DNA repair [49].

\section{DNA repair}

Loss of HMGB1 or increased HMGB1 translocation from the nucleus to the cytoplasm increases DNA damage, decreases DNA repair efficiency, and intensifies cell response to various stimuli such as chemotherapy, irradiation and oxidative stress (Figure 3). There are two hypotheses of HMGB1 on the repair of damaged DNA. One is the "repair shielding" hypothesis, proposing that the binding of HMGB1 to the DNA lesion can block the access of the repair machinery [56]. The other is "repair enhancement" hypothesis, deducing that HMGB1 can bind and bend damaged DNA cooperatively with excision repair damage recognition proteins [57]. It has been shown that HMGB1 participated in all four major DNA repair pathways: mismatch repair (MMR) [58], base excision repair (BER) [59], double-strand break repair (DSBR) [60] and nucleotide excision repair (NER) [61]. HMGB1 bond to damaged DNA, altered DNA structures, interacted with repair enzymes or cofactors, and remodeled chromatin. Thus, dubbed HMGB1 the "jackof-all-trades" repair protein [56]. Early researches found that HMGB1 specifically bond to damaged DNA isolated from cells treated with cisplatin $[62,63]$. Cispaltin induces 1,2-intrastrand $d(\mathrm{GpG})$ and $d(\mathrm{ApG})$ cross-links in DNA. To repair this DNA lesion, NER, one of the cellular defense mechanisms against the toxic effects of cisplatin, is involved that links HMGB1 to this repair pathway [64]. Non-homologous end-joining (NHEJ) is the main DSBR pathway to ligate the damaged DNA ends of DSBs, which HMGB1 is believed to participate in several steps of NHEJ repair pathway. Purified HMGB1 has been reported to bind to the ends of DSBs and stimulate the activity of DNAdependent protein kinase in vitro [65]. However, whether HMGB1 plays similar role in NHEJ repair of DSBs in vivo has been seldom studied. HMGB1 is identified as a participant in MMR as well. It is involved in the initial damage recognition/incision steps of heteroduplex repair and interaction with the MMR proteins MSH2 and MLH1 [58]. HMGB1 is confirmed to be responsible for cisplatin resistance in esophageal squamous cell carcinoma (ESCC) [66]. HMGB1 contributes to the repair of DNA damage and cells, lacking HMGB1, are hypersensitive to DNA damage precipitating factors [57].

\section{Transcription}

The role of HMGB1 in gene transcription is either an activator or a repressor (Figure 3). Generally, HMGB1 can bend DNA and facilitate the binding of transcription factors to their cognate DNA sequences and enhance their activities, such as p53 [67], p73 [68], estrogen receptor (ER) [69], replication and transcription activator (RTA)

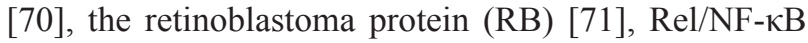
[72]. P53 is the most frequently altered gene in human carcinoma. Previous studies have implicated that p53 carboxyl terminus negatively regulates its binding to DNA. Carboxy-terminally deleted p53 is observed to be constitutively active for DNA binding. However, the regulation of HMGB1 on p53 DNA binding is independent from that involving p53 carboxyl terminus. It is reported that HMGB1 induced DNA bending can provide prebent consensus site DNA to p53 and increase p53 activity [73]. The bent DNA can also recruit additional transcription factors in close vicinity and facilitate their mutual functions [49]. Moreover, HMGB1 can enhance DNA flexibility by looping and bring transcription factors bound on distant regulatory sequences into close proximity, which results in mutual contacts [49]. Additionally, it has been demonstrated that the HMGB1 can promote DNA binding of transcription activators without direct interactions between HMGB1 and transcription activators [74]. Besides, HMGB1 has been reported to act as a negative cofactor and repress transcription by RNA polymerase II. It binds to the TATA-binding protein (TBP) to form the HMGB1/TBP/TATA complex and prevents the recruitment of transcription factor IIB (TFIIB, a initiation factor) to this complex, subsequently inhibits the assembly of the pre-initiation complex (PIC) [75].

\section{Telomere and telomerase}

Telomeres are repetitive DNA sequences, consisting of two main core components: a catalytic protein subunit (telomerase reverse transcriptase, TERT) and an RNA subunit (telomerase RNA, TR) [76]. The telomere maintenance is believed to be a component of tumor cell unlimited replicative potential. HMGB1 is reported to modulate cellular activity of mammalian telomerase (Figure 3). Knockout of the HMGB1 gene in mouse embryonic fibroblasts (MEFs) results in telomere dysfunction and reduced telomerase activity, while overexpression of HMGB1 enhances telomerase activity [76]. The maintenance and protection of telomeres are also modulated by shelterin, which is composed of protection of telomere 1 (POT1), telomeric-repeat-binding factor 1 (TRF1), TRF1-interacting protein 2 (TIN2), the TIN2 and POT1 interacting protein 1 (TPP1), telomeric-repeatbinding factor 2 (TRF2) and the transcriptional repressor/ activator protein (RAP1). Through the interaction with telomerase, this shelterin can control the telomere length to maintain the stability of telomeres [77]. Knockdown of HMGB1 modulates telomere homeostasis by downregulating expressions of telomere-binding proteins TTP1 and TRF1, thereby initiating apoptosis and increasing radiosensitivity in human breast cancer cells [78].

\section{Cytosolic function of HMGB1}

\section{Autophagy}

The main function of cytoplasmic HMGB1 is autophagy modulation (Figure 3). Autophagy is a lysosomal degradation process that clears long-lived 
or dysfunctional proteins and organelles for cell survival during periods of starvation or other microenvironmental stresses. Stimuli that enhance reactive oxygen species facilitate translocation of HMGB1 to cytoplasm and enhance autophagic flux. It is demonstrated that the dissociation of Bcl-2 from Beclin 1 is an important mechanism in autophagy activation. Cytosolic HMGB1 can disrupt the interaction between Beclin 1 and Bcl-2 by directly binding to Beclin-1 with its intramolecular disulfide bridge (C23/45) and sustain autophagy [9]. Cytoplasts (anucleate cells) have been created to assess the role of cytoplasmic HMGB1 in the setting of autophagy. HMGB1 KO MEF cytoplasts shows a lower level of LC3 punctae than HMGB1 wild-type MEF cytoplasts in response to starvation, indicating that cytoplasmic HMGB1 is required for starvation-stimulated autophagy [9]. A series of studies have confirmed that Beclin 1 binds to $\mathrm{Bcl}-2$ via its $\mathrm{BH} 3$ domain that can be modified by JNK or ERK signaling pathway. HMGB1 can increase transcriptional activities of JNK and ERK pathway in human myeloid leukemia cells, which results in phosphorylation of Bcl-2 and its binding to Beclin1 [79]. HMGB1 and p53, the most frequently mutated gene in human cancers, are both implicated in regulation of balance between autophagy and apoptosis [80]. The function of p53 in autophagy is controlled by its subcellular localization. Generally, cytoplasmic p53 represses autophagy, while nuclear p53 stimulates autophagy [80]. It is demonstrated that HMGB1 and p53 form a complex that regulates the cytoplasmic localization of the binding protein and subsequent levels of autophagy. P53 $3^{<\text {sup }>-/-</ \text { sup }>}$ HCT116 cells rapidly increase expression of cytosolic HMGB1 and associated autophagy in response to stress. Conversely, HMGB1 $1^{<\text {sup }>-1-</ \text { sup }>}$ MEFs increase cytosolic translocation of p53 and decrease autophagy in response to stress. Interestingly, it is reported that HMGB1 does not influence p53-dependent expression of damageregulated autophagy modulator (DRAM) and unc-51like 1 (ULK1) within the nucleus during autophagy. However, HMGB1 is required for induction of autophagy when p53 is knockout or pharmacological inhibited, suggesting HMGB1 regulates the cytoplasmic but not the nuclear function of p53 during autophagy [80, 81].

\section{Cell proliferation}

Human mitochondrial DNA (mtDNA) is a 16569 bp, maternally inherited, closed circular double-stranded DNA molecule. The content of mtDNA is precisely modulated by cellular physiological conditions and diverse internal or external microenvironments, such as hypoxia and steroid hormone stimulation [82]. Amounts of evidence have supported a critical role of mtDNA in a broad range of human cancers and contributing to cancer commencement and promotion at various stages of oncogenesis [82]. It is shown that cytoplasmic HMGB1 senses and binds to mtDNA via sensing the $\mathrm{CpG}$ rich motifs in mtDNA. During hypoxia, HMGB1 translocates from nucleus to the cytosol, binds to mtDNA released from damaged mitochondria, and subsequently activates TLR9 signaling pathway to promote tumor cell proliferation [83]. Loss of HMGB1 leads to a defect in TLR9 signaling pathway and decreases tumor cell proliferation, whereas addition of HMGB1 leads to the activation of TLR9 signaling pathway and promotes tumor cell proliferation [83] (Figure 3).

\section{Secretion}

Lee et al. identified 74 putative HMGB1-binding proteins localized exclusively in the extra-nuclear region, and 60 proteins bond HMGB1 both in the nucleus and extra-nuclear region. Many of these binding proteins are important in carcinogenesis, such as cell cycle progression (40S ribosomal protein $\mathrm{S} 15 \mathrm{a}$ and serum albumin precursor), cell proliferation (40S ribosomal protein $\mathrm{S} 15 \mathrm{a}, 40 \mathrm{~S}$ ribosomal protein $\mathrm{S} 4, \mathrm{X}$ isoform, coffilin-1, nucleophosmin and protein arginine $\mathrm{N}$-methyltransferase 5), angiogenesis (annexin 2, ATP synthase subunit beta, myosin heavy chain 9, serum albumin precursor and nucleolin) and anti-apoptosis (alpha actinin-4, coffilin-1, HSPA5 protein and nucleophosmin). Besides, there are nine HMGB1-binding proteins related to intracellular protein transport and secretion, including alpha actinin-4, nucleophosmin, myosin IC isoform a, protein-enabled homologue, splicing factor, arginine/serine-rich 1, Ras-related protein Rab-10, annexin A2 and dpy-30 homologue (DPY30) [44]. Most secreted proteins have a signal peptide that directs their translocation to ER and collectively form secretome, which is also known as the conventional secretory pathway [84]. However, there is no signal peptide in HMGB1, predicting that HMGB1 is secreted via the unconventional secretory pathway. Moreover, studies have proved that these nine HMGB1binding proteins are associated with the unconventional secretory pathway. For instant, myosin IC isoform a and Ras-related protein Rab-10 regulate vesicular transport and involved in protein secretion. DPY30 is involved in endosomal transport. Annexin A2 functions in aggregation and membrane fusion of phospholipid-containing vesicles. In addition, cytosolic HMGB1 is relevant to the lysosome and co-localized with lysosomal protein LAMP1 by immunofluorescence confocal microscopy [44]. These findings indicate that the secretion of HMGB1 is via the unconventional secretory pathway, particularly via secretory lysosomes [44] (Figure 3).

\section{Membrane function of HMGB1}

The functions of HMGB1 on cell surface include platelet activation [85], erythroid maturation [86] and innate immunity [87]. In human resting platelets, HMGB1 and its mRNA are localized in the cytoplasm. When platelets are activated, part of HMGB1 could export to the 
external surface of platelets. While in the platelet surface, HMGB1 could enhance the rate of plasminogen activation and promote the generation of surface-bound plasmin [85]. Studies have showed that HMGB1 expressed on the surface of erythroblasts and macrophages involves in erythroblast-macrophage contact to promote erythroid cells proliferation and terminal maturation [86]. To characterize the role of HMGB1 in the innate immunity of newborns, Ciucci et al utilize flow cytometry and western blot to analyze HMGB1 expression in human cord blood (CB) mononuclear cells and adult peripheral blood (PB) mononuclear cells [87]. The results show that HMGB1 is expressed on cell surface membranes of myeloid dendritic cell precursors and lymphocytes, which can be upregulated by pro-inflammatory stimuli and subsequently secreted into extracellular environment. These secreted HMGB1 enhance the immune response in $\mathrm{CB}$ via engagement of $\gamma \delta$ T lymphocytes and myeloid dendritic cell precursors [87]. Additionally, it has been proposed that HMGB1 present at the cell surface promotes cell migration and tumor metastasis [45] (Figure 3).

\section{Extracellular function of HMGB1}

Extracellular HMGB1 acts as a DAMP with cytokine and chemokine activities, leading to various responses, such as cell proliferation, invasion, metastasis, angiogenesis, inflammation and immunity (Figure 3).

\section{Cell proliferation}

Extracellular HMGB1 regulates cell proliferation in several cells via different mechanisms. It is reported that HMGB1 releases from human malignant mesothelioma cells and promotes proliferation of these cells via an autocrine circuit [88]. Exogenous HMGB1 induces mouse mesangial cell proliferation by promoting the cell cycle transition from G0/G1 to S phase [89]. Tumor cells require adenosine triphosphate (ATP) to support proliferation. Exogenous HMGB1 and RAGE coordinately contribute to tumor cell ATP production and subsequent cell proliferation in a time- and dose-dependent manner. It is also observed that endogenous HMGB1 increases mitochondrial RAGE expression, which is associated with tumor cell ATP production via MEK-ERK-MAPK pathway. Lack of RAGE or inhibition of HMGB1 reduces ATP production and slows pancreatic cancer cell growth [90]. However, this proliferative effect varies in different cell types. Chitanuwat et al. investigate that human recombinant HMGB1 can significantly induce the proliferation of human gingival fibroblasts, which is not obvious in human periodontal ligament fibroblasts [91].

\section{Invasion and metastasis}

The finding outlined in elucidating the role of extracellular HMGB1 in regulation of tumor cell invasion and metastasis is controversial. In some studies, the interaction of extracellular HMGB1 and RAGE induces
NF-кB activation or MAPK signaling pathway to promote tumor cell invasion and metastasis $[18,92]$. Extracellular HMGB1 activates TLR4 and RAGE signal pathways, subsequently the downstream of caspase-1, and then pro-inflammatory cytokines IL- $1 \beta$ and IL-18 are cleaved and released, which in turn promote $\mathrm{HCC}$ invasion and metastasis in hypoxia. Treatment with HMGB1 reinforces the invasion of HCC cells [93]. However, Zuo et al. demonstrate that knockdown of HMGB1 increases cancer cell migration, invasion and metastasis in vitro and in vivo, which can be inhibited by recombinant human HMGB1, indicating that the inhibitory effect on cell migration is dependent on the HMGB1 in the microenvironment. They also discovers that this inhibitory effect of extracellular HMGB1 is via suppressing phosphorylation, nuclear translocation and activation of cyclic AMP response element-binding protein (CREB), which further reduces neuron Wiskott-Aldrich syndrome protein (nWASP) expression [94].

\section{Angiogenesis}

Angiogenesis is essential for the progression of most solid tumors. The vessel formation of these tumors depends on pro- and anti-angiogenic factors in tumor microenvironments. Endothelial cells (ECs) play pivotal roles in tumor angiogenesis and provide attractive novel therapeutic targets. Gene expression profiling results of ECs isolated from freshly resected colorectal tumors, normal colon tissue and placenta showed that HMGB1 was a tumor angiogenesis gene [95]. In vitro and in vivo $\mathrm{HMGB} 1$ can stimulate the migratory and sprouting capacity of ECs, which can be attenuated by interference in HMGB1 expression. Antibodies of HMGB1 inhibit tumor angiogenesis in chicken embryo chorioallantoic membrane (CAM) model [96]. In human oral squamous cell carcinoma, HMGB1 promotes VEGF secretion via binding to RAGE. Down-regulation of RAGE abrogates this effect [97]. HMGB1 can also provoke the recruitment and activation of macrophages to produce angiogenic factors such as vascular endothelial growth factor (VEGF), tumor necrosis factor- $\alpha$ (TNF- $\alpha$ ) and interleukin-8 (IL-8) for vasculature formation [98]. Interestingly, HMGB1 has also been observed to improve tumor neovascularization by attracting endothelial progenitor cells (EPCs) and mesoangioblasts [99]. EPCs and mesoangioblasts could both differentiate into ECs, and HMGB1 could promote these two cell types to the site of tumors for angiogenesis [100].

\section{Apoptosis evasion}

Apoptosis is mainly activated through two alternative pathways: the intrinsic pathway triggered by mitochondria and the extrinsic pathway mediated by cell death receptors. Cysteine aspartyl-specific proteases (caspases) that cleave cellular substrates lead to the biochemical and morphological changes of apoptotic cells in both pathways [101]. Crosstalk between HMGB1 
and apoptosis has been explored in many cancer cells. Down-regulation of HMGB1 with microRNA 34a, a tumor suppressor gene, leads to inhibition of autophagy and promotes DNA damage in the retinoblastoma cell. Subsequently, the CASP3 and poly (ADP-ribose) polymerase 1 (PARP1) are cleaved, which are important to the apoptotic process. Knockdown of HMGB1 by shRNA similarly induces apoptosis in retinoblastoma cells [102]. Extracellular HMGB1 can protect gastric cancer cells from apoptosis induced by vincristine via transcriptional up-regulation of myeloid cell leukemia-1 (Mcl-1, an anti-apoptotic member of the Bcl-2 protein family). This protective effect can be abolished by knockdown of HMGB1 or inhibition of its release. Additionally, the release of HMGB1 is caused by vincristine-induced cell autophagy, and the up-regulation of Mcl-1 mRNA is mainly through RAGE-mediated signaling, partly through TLR2- and TLR4-mediated signaling [103]. However, several reports have indicated that extracellular HMGB1 is cytotoxic and leads to cell death [104]. Extracellular HMGB1 can induce a special form of cell death in glioblastoma cells, which is accompanied by the formation of vacuolated giant mitochondria and a rapid depletion of mitochondrial DNA (mtDNA). This distinct mode of cell death differs from apoptosis, autophagy, and senescence. The giant mitochondria-associated rhHMGB1-induced cell death is induced by exogenous HMGB1 internalization to mitochondria, independent of TLR2, TLR4, or RAGE signaling [104].

\section{Inflammation}

The mechanism of tumor progression has been shown to be associated with the local inflammatory reactions, especially chronic persistent inflammation. Extracellular HMGB1 is considered as a proinflammatory cytokine in this inflammation-associated tumorigenesis [88]. Extracellular HMGB1 can promote NFкB transportation to the nucleus and induce expression of inflammatory factor and tumor cell proliferation via TLR4 signaling pathway [105, 106]. HMGB1 is also recognized as an important mediator of p53-dependent hepatic inflammation that exerts a critical pathogenic role in hepatocarcinogenesis. Sustained p53 activation in response to a persistent DNA damage signal, leads to HMGB1 release, which drives pro-tumorigenic liver inflammation. Inhibition of HMGB1 release mitigates carcinogen-induced hepatic injury and tumorigenesis [107]. In addition, extracellular HMGB1 can induce both recruited leukocytes and settled immune cells to release cytokines such as TNF, IL-1 and IL-6, which amplifies and extends the inflammatory response [108].

\section{Immunity}

Cancer immunity surveillance is an important host defense process to maintain cellular homeostasis. HMGB1 has been characterized as both immune suppression and immune activation properties, which depends on receptors, targeted cells and redox state [54]. HMGB1 has the ability to mature DCs and support the clonal expansion of $\gamma$-interferon producing Th1 cells [109]. Immunogenic cell death (ICD) is a cell death modality that stimulates immune response against dead cell antigens. The immunogenic characteristics of ICD are mainly mediated by DAMPs, which include released HMGB1 [110]. In the resting state of diffuse large B-cell lymphoma (DLBCL) cells, HMGB1 co-localized and interacts with STAT3 in the nucleus. Treatment of rituximab induces an inhibition on STAT3 activity and triggers a rapid HMGB1 release and IL-10 reduction in DLBCL patients' serum. The medium from rituximab-treated DLBCL cells is competent for phagocytosis, dendritic cells maturation, and IFN- $\gamma$ secretion by cytotoxic T cells, which elicits immune responses [111]. Immune tolerance is essential for a functioning immune system and any approximation of self-nonself discrimination. It is reported that the released HMGB1 from dying cells can be oxidized via caspase dependent production of reactive oxygen species in mitochondria of apoptotic cells, which promotes immunological tolerance [112]. The immune tolerance can be abrogated by blocking oxidation of cysteine resides in HMGB1 at positions C106, suggesting that the oxidation/ reduction status of cysteine in HMGB1 is responsible for immunogenicity and tolerance of dying cells [112].

\section{HMGB1 IN ANTICANCER THERAPY}

Currently, several strategies have been proposed to inhibit HMGB1 expression, activity and release in a direct or indirect manner for treatment of cancer as well as various inflammatory diseases (Figure 4).

\section{Inhibitors of HMGB1 protein}

Administration of anti-HMGB1 antibody inhibits liver metastasis of colorectal cancer, suggesting that HMGB1 is a promising target for metastasis inhibition [113]. Anti-HMGB1 neutralizing antibody also significantly decreases the effect of released extracellular HMGB1 from cancer-associated fibroblasts or recombinant HMGB1 on doxorubicin (DOX) resistant breast cancer cells [114]. HMGB1 box A can be utilized as a competitive HMGB1 antagonist and block HMGB1associated inflammation and cancer [5]. Knockdown of HMGB1 using antisense oligodeoxynucleic acid technology inhibits cancer cell growth and metastasis $[18,115]$. Glycyrrhizin (GR), a triterpenoid saponin glucoside of glycyrrhizic acid, can specifically bind to both HMG boxes of HMGB1 and inhibit its chemotactic and mitogenic activities [7, 116]. It has been investigated that GR can protect spinal cord, liver, brain and myocard against ischemia-reperfusion induced injury in animal models by inhibiting HMGB1 cytokine activity [7, 117]. During anticancer therapy, HMGB1 favors to release 
into the extracellular milieu, which has positive effects on tumor relapse, such as stimulation of cancer cell proliferation, angiogenesis, cell motility and inflammation. As HMGB1 inhibitor, GR impedes HMGB1 induced tumor cell proliferation, migration, blood vessels formation and inflammatory condition [118].

\section{Targeting receptors}

Blockade of HMGB1-RAGE signaling has been observed to suppress tumor growth and metastasis in implanted tumors [92]. Inhibition of the HMGB1RAGE interaction suppresses activation of MAP kinases, which are the important molecular effector mechanisms linking to tumor progression [92]. Soluble RAGE is an endogenous truncated form of RAGE consisting of the extracellular domain of RAGE, which acts as a decoy to block HMGB1-RAGE signaling pathway in animal tumor models $[92,119]$.

\section{Inhibition of HMGB1 secretion}

It is well known that monocytes and macrophages can secrete HMGB1 under various stress stimuli $[16,46]$.
Some cancer cells also have the ability to secrete HMGB1 themselves into the culture media, such as colon cancer and malignant mesothelioma [120, 121]. Current investigations have focused on pharmacological inhibition of HMGB1 secretion. Ethyl pyruvate (EP), a pyruvic acid derivative, is the first described pharmacological inhibitor for HMGB1 secretion. EP impairs HMGB1 secretion by malignant mesothelioma cells and downregulates RAGE expression and NF$\kappa \mathrm{B}$ activation. Moreover, EP reduces HMGB1 serum levels in mice and inhibits the growth of malignant mesothelioma xenografts [122]. As an antioxidant, quercetin reduces circulating level of HMGB1 in animals with established endotoxemia. In macrophage cultures, quercetin inhibits release as well as the cytokine activities of HMGB1 [123]. Glycyrrhizin is also utilized as a HMGB1 secretion inhibitor. It is reported that glycyrrhizin can inhibit HMGB1 phosphorylation and secretion by directly binding to HMGB1 and interacting with two shallow concave surfaces formed by the tow arms of both HMG boxes [124]. Macrophage treatment with nicotine showed prevention of HMGB1 secretion and inhibited activation of $\mathrm{NF}-\kappa \mathrm{B}$ signaling pathway [125].

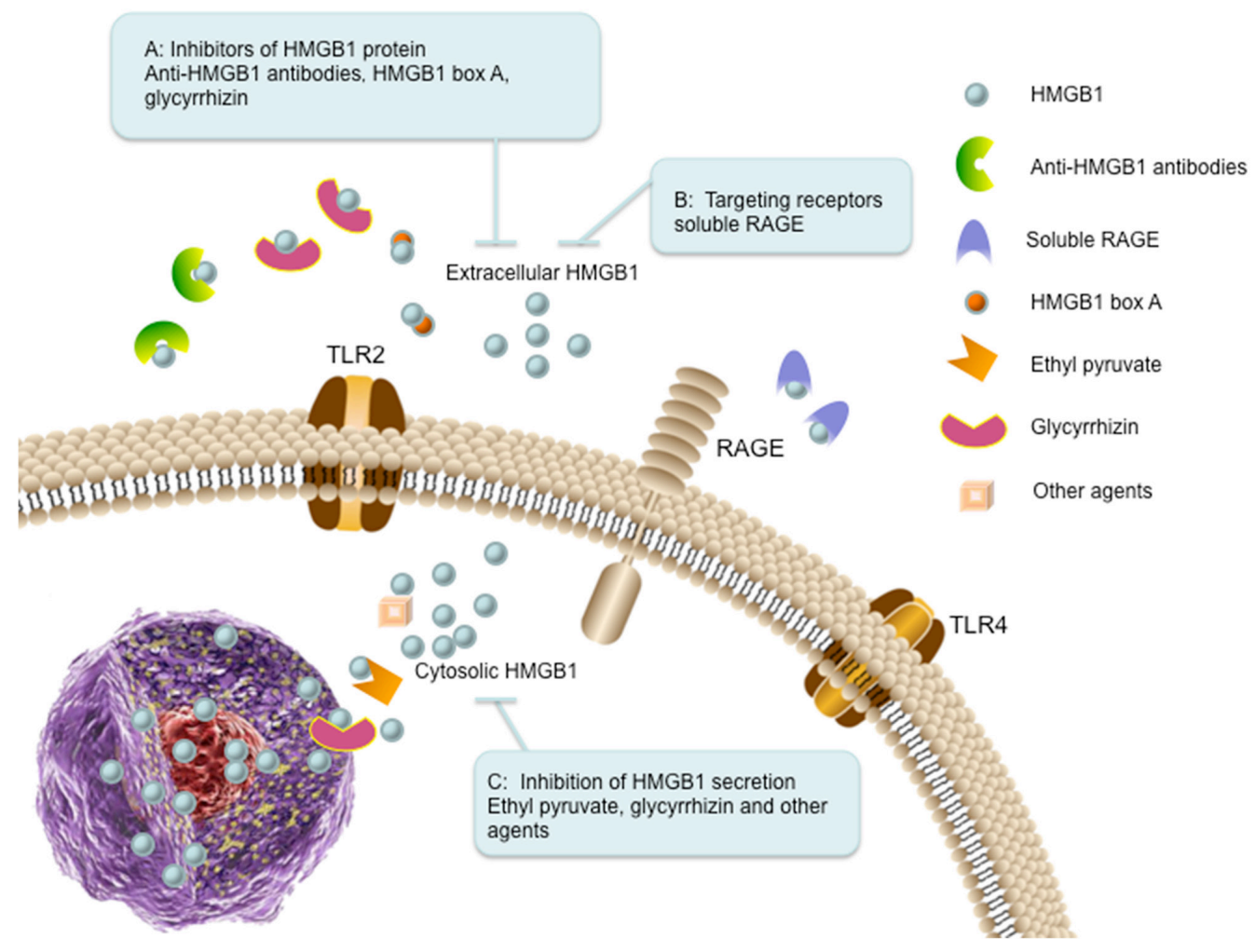

Figure 4: The therapeutic strategies targeting HMGB1 in cancer. (A) Inhibitors of HMGB1 protein. Extracellular HMGB1 can be blocked by administration of anti-HMGB1 antibodies (binds to HMGB1), HMGB1 box A (antagonizes the B box functional activity of HMGB1), and glycyrrhizin (binds to HMGB1). (B) Targeting receptors. Soluble RAGE (sRAGE) acts as a decoy to block HMGB1-RAGE signaling pathway. (C) Inhibition of HMGB1 secretion. The secretion of HMGB1 can be inhibited by ethyl pyruvate, glycyrrhizin and other agents (such as quercetin and nicotine). 


\section{CONCLUSION}

HMGB1 is involved in multiple biologic process of cancer, such as tumor growth, tumor cell proliferation, invasion and metastasis. In nucleus, HMGB1 acts as a tumor suppressor via various mechanisms to sustain genome stability, while out of nucleus, it acts as either tumor supporter or tumor suppressor. For instance, extracellular HMGB1 is conducive to ICD-associated antitumor immunity in the early stages of chemotherapy, while it facilitates residual tumor cell survival in the late stages of chemotherapy. Other studies have showed that the redox of HMGB1 plays an important role in tumor cell death and survival. Therefore, the first prerequisite is whether to design a HMGB1 inducer or inhibitor when considering HMGB1 targeted therapeutic, and the targeted treatment of cancer varies at different stages.

Numerous strategies have being employed to restrain the activity and release of HMGB1 in anti-cancer therapeutics. However, there are still flaws in these strategies. It is reported that HMGB1-deficient mice are born alive, but die within $24 \mathrm{~h}$ due to hypoglycaemia [126]. Inhibition of HMGB1 in nuclear can induce insufficient transcription or DNA repair in normal cells [49]. HMGB1 inhibitor or neutralizing antibody also abates immune response to virus infection and tumor antigen via blocking HMGB1/TLR4 signaling pathway [22]. Accordingly, neutralizing monoclonal antibody of HMGB1 should incorporate the fact that HMGB1/ TLR4 signaling modulates inflammatory responses while HMGB1/RAGE signaling promotes tumor growth and metastasis $[18,22]$. Moreover, apart from HMGB1, there are several other ligands for RAGE such as S100B and $\mathrm{S} 100 \mathrm{P}$, which are associated with pro-inflammatory activation [127]. Thus, strategies targeting RAGE receptor impair S100B and S100P related functions. The release of HMGB1 is affected by many factors such as cytokines, oxidative stress and cellular stresses. Therefore, interference with HMGB1 release should take all these factors into consideration. Although much attention has been paid on the redox statuses of HMGB1, especially its effect on tumor cell autophagy and apoptosis [128], it is still unknown about how signaling pathways are regulated by different redox forms of HMGB1.

Indeed, HMGB1 has been proved to be a successful therapeutic target in experimental models of diverse infectious and inflammatory diseases [129]. There are no ongoing clinical trials for HMGB1 targeted agents in patients with cancer so far. Further basic and clinical studies are warranted to exploit the explicit structure, location and partners of HMGB1, especially multiple functions of HMGB1 in regulating tumor cell survival and death. Considering the essential role of HMGB1 in innate immunity, methods for local inhibition of HMGB1 need to be invented for the safety of HMGB1 targeting therapy.

\section{CONFLICTS OF INTEREST}

The authors have no other relevant affiliations or financial involvement with any organization or entity with a financial interest in or financial conflict with the subject matter or materials discussed in the manuscript apart from those disclosed.

\section{GRANT SUPPORT}

This research is supported by grants from the National Natural Science Foundation of China (81572951) (Qian Huang) and (81502648) (Jin Cheng).

\section{REFERENCES}

1. Goodwin GH, Sanders C, Johns EW. A new group of chromatin-associated proteins with a high content of acidic and basic amino acids. Eur J Biochem. 1973; 38:14-19.

2. Guo ZS, Liu Z, Bartlett DL, Tang D, Lotze MT. Life after death: targeting high mobility group box 1 in emergent cancer therapies. Am J Cancer Res. 2013; 3:1-20.

3. Landsman D, Bustin M. A signature for the HMG-1 box DNA-binding proteins. Bioessays. 1993; 15:539-546.

4. Diener KR, Al-Dasooqi N, Lousberg EL, Hayball JD. The multifunctional alarmin HMGB1 with roles in the pathophysiology of sepsis and cancer. Immunol Cell Biol. 2013; 91:443-450.

5. Li JH, Kokkola R, Tabibzadeh S, Yang RK, Ochani M, Qiang XL, Harris HE, Czura CJ, Wang HC, Ulloa L, Wang H, Warren HS, Moldawer LL, et al. Structural basis for the proinflammatory cytokine activity of high mobility group box 1. Mol Med. 2003; 9:37-45.

6. Ellerman JE, Brown CK, de Vera M, Zeh HJ, Billiar T, Rubartelli A, Lotze MT. Masquerader: high mobility group box-1 and cancer. Clin Cancer Res. 2007; 13:2836-2848.

7. Musumeci D, Roviello GN, Montesarchio D. An overview on HMGB1 inhibitors as potential therapeutic agents in HMGB1-related pathologies. Pharmacol Ther. 2014; 141:347-357.

8. Wang Q, Zeng M, Wang W, Tang J. The HMGB1 acidic tail regulates HMGB1 DNA binding specificity by a unique mechanism. Biochem Biophys Res Commun. 2007; 360:14-19.

9. Tang D, Kang R, Livesey KM, Cheh CW, Farkas A, Loughran P, Hoppe G, Bianchi ME, Tracey KJ, Zeh HJ 3rd, Lotze MT. Endogenous HMGB1 regulates autophagy. J Cell Biol. 2010; 190:881-892.

10. Hoppe G, Talcott KE, Bhattacharya SK, Crabb JW, Sears JE. Molecular basis for the redox control of nuclear transport of the structural chromatin protein Hmgb1. Exp Cell Res. 2006; 312:3526-3538.

11. Sparvero LJ, Asafu-Adjei D, Kang R, Tang D, Amin N, Im J, Rutledge R, Lin B, Amoscato AA, Zeh HJ, Lotze MT. 
RAGE (Receptor for Advanced Glycation Endproducts), RAGE ligands, and their role in cancer and inflammation. $\mathrm{J}$ Transl Med. 2009; 7:17.

12. Raucci A, Cugusi S, Antonelli A, Barabino SM, Monti L, Bierhaus A, Reiss K, Saftig P, Bianchi ME. A soluble form of the receptor for advanced glycation endproducts (RAGE) is produced by proteolytic cleavage of the membrane-bound form by the sheddase a disintegrin and metalloprotease 10 (ADAM10). FASEB J. 2008; 22:3716-3727.

13. Sessa L, Gatti E, Zeni F, Antonelli A, Catucci A, Koch M, Pompilio G, Fritz G, Raucci A, Bianchi ME. The receptor for advanced glycation end-products (RAGE) is only present in mammals, and belongs to a family of cell adhesion molecules (CAMs). PLoS One. 2014; 9:e86903.

14. Sorci G, Riuzzi F, Giambanco I, Donato R. RAGE in tissue homeostasis, repair and regeneration. Biochim Biophys Acta. 2013; 1833:101-109.

15. Yaser AM, Huang Y, Zhou RR, Hu GS, Xiao MF, Huang ZB, Duan CJ, Tian W, Tang DL, Fan XG. The Role of receptor for Advanced Glycation End Products (RAGE) in the proliferation of hepatocellular carcinoma. Int J Mol Sci. 2012; 13:5982-5997.

16. Sims GP, Rowe DC, Rietdijk ST, Herbst R, Coyle AJ. HMGB1 and RAGE in inflammation and cancer. Ann Rev Immunol. 2010; 28:367-388.

17. Gebhardt C, Riehl A, Durchdewald M, Nemeth J, Furstenberger G, Muller-Decker K, Enk A, Arnold B, Bierhaus A, Nawroth PP, Hess J, Angel P. RAGE signaling sustains inflammation and promotes tumor development. J Exp Med. 2008; 205:275-285.

18. Chen RC, Yi PP, Zhou RR, Xiao MF, Huang ZB, Tang DL, Huang Y, Fan XG. The role of HMGB1-RAGE axis in migration and invasion of hepatocellular carcinoma cell lines. Mol Cell Biochem. 2014; 390:271-280.

19. Pradere JP, Dapito DH, Schwabe RF. The Yin and Yang of Toll-like receptors in cancer. Oncogene. 2014; 33:3485-3495.

20. O'Neill LA, Fitzgerald KA, Bowie AG. The Toll-IL-1 receptor adaptor family grows to five members. Trends Immunol. 2003; 24:286-290.

21. Dajon $\mathrm{M}$, Iribarren $\mathrm{K}$, Cremer I. Toll-like receptor stimulation in cancer: a pro- and anti-tumor double-edged sword. Immunobiology. 2017; 222:89-100.

22. Apetoh L, Ghiringhelli F, Tesniere A, Obeid M, Ortiz C, Criollo A, Mignot G, Maiuri MC, Ullrich E, Saulnier P, Yang H, Amigorena S, Ryffel B, et al. Toll-like receptor 4-dependent contribution of the immune system to anticancer chemotherapy and radiotherapy. Nat Med. 2007; 13:1050-1059.

23. Laird MD, Shields JS, Sukumari-Ramesh S, Kimbler DE, Fessler RD, Shakir B, Youssef P, Yanasak N, Vender JR, Dhandapani KM. High mobility group box protein-1 promotes cerebral edema after traumatic brain injury via activation of toll-like receptor 4 . Glia. 2014; 62:26-38.
24. Herzog C, Lorenz A, Gillmann HJ, Chowdhury A, Larmann J, Harendza T, Echtermeyer F, Muller M, Schmitz M, Stypmann J, Seidler DG, Damm M, Stehr SN, et al. Thrombomodulin's lectin-like domain reduces myocardial damage by interfering with HMGB1-mediated TLR2 signalling. Cardiovasc Res. 2014; 101:400-410.

25. Tian J, Avalos AM, Mao SY, Chen B, Senthil K, Wu H, Parroche P, Drabic S, Golenbock D, Sirois C, Hua J, An LL, Audoly L, et al. Toll-like receptor 9-dependent activation by DNA-containing immune complexes is mediated by HMGB1 and RAGE. Nat Immunol. 2007; 8:487-496.

26. Bamboat ZM, Balachandran VP, Ocuin LM, Obaid H, Plitas G, DeMatteo RP. Toll-like receptor 9 inhibition confers protection from liver ischemia-reperfusion injury. Hepatology. 2010; 51:621-632.

27. Sakuishi K, Jayaraman P, Behar SM, Anderson AC, Kuchroo VK. Emerging Tim-3 functions in antimicrobial and tumor immunity. Trends Immunol. 2011; 32:345-349.

28. Monney L, Sabatos CA, Gaglia JL, Ryu A, Waldner H, Chernova T, Manning S, Greenfield EA, Coyle AJ, Sobel RA, Freeman GJ, Kuchroo VK. Th1-specific cell surface protein Tim-3 regulates macrophage activation and severity of an autoimmune disease. Nature. 2002; 415:536-541.

29. Tang D, Lotze MT. Tumor immunity times out: TIM-3 and HMGB1. Nat Immunol. 2012; 13:808-810.

30. Ndhlovu LC, Lopez-Verges S, Barbour JD, Jones RB, Jha AR, Long BR, Schoeffler EC, Fujita T, Nixon DF, Lanier LL. Tim-3 marks human natural killer cell maturation and suppresses cell-mediated cytotoxicity. Blood. 2012; 119:3734-3743.

31. Chiba S, Baghdadi M, Akiba H, Yoshiyama H, Kinoshita I, Dosaka-Akita H, Fujioka Y, Ohba Y, Gorman JV, Colgan JD, Hirashima M, Uede T, Takaoka A, et al. Tumorinfiltrating DCs suppress nucleic acid-mediated innate immune responses through interactions between the receptor TIM-3 and the alarmin HMGB1. Nat Immunol. 2012; 13:832-842.

32. Kuil J, Buckle T, van Leeuwen FW. Imaging agents for the chemokine receptor 4 (CXCR4). Chem Soc Rev. 2012; 41:5239-5261.

33. Bleul CC, Farzan M, Choe H, Parolin C, Clark-Lewis I, Sodroski J, Springer TA. The lymphocyte chemoattractant SDF-1 is a ligand for LESTR/fusin and blocks HIV-1 entry. Nature. 1996; 382:829-833.

34. Li YM, Pan Y, Wei Y, Cheng X, Zhou BP, Tan M, Zhou X, Xia W, Hortobagyi GN, Yu D, Hung MC. Upregulation of CXCR4 is essential for HER2-mediated tumor metastasis. Cancer Cell. 2004; 6:459-469.

35. Ratajczak MZ, Zuba-Surma E, Kucia M, Reca R, Wojakowski W, Ratajczak J. The pleiotropic effects of the SDF-1-CXCR4 axis in organogenesis, regeneration and tumorigenesis. Leukemia. 2006; 20:1915-1924. 
36. Schiraldi M, Raucci A, Munoz LM, Livoti E, Celona B, Venereau E, Apuzzo T, De Marchis F, Pedotti M, Bachi A, Thelen M, Varani L, Mellado M, et al. HMGB1 promotes recruitment of inflammatory cells to damaged tissues by forming a complex with CXCL12 and signaling via CXCR4. J Exp Med. 2012; 209:551-563.

37. Kew RR, Penzo M, Habiel DM, Marcu KB. The IKK alpha-dependent NF-kappa B p52/RelB noncanonical pathway is essential to sustain a CXCL12 autocrine loop in cells migrating in response to HMGB1. J Immunol. 2012; 188:2380-2386

38. Muller S, Ronfani L, Bianchi ME. Regulated expression and subcellular localization of HMGB1, a chromatin protein with a cytokine function. J Intern Med. 2004; 255:332-343.

39. Mosevitsky MI, Novitskaya VA, Iogannsen MG, Zabezhinsky MA. Tissue specificity of nucleo-cytoplasmic distribution of HMG1 and HMG2 proteins and their probable functions. Eur J Biochem. 1989; 185:303-310.

40. Degryse B, Bonaldi T, Scaffidi P, Muller S, Resnati M, Sanvito F, Arrigoni G, Bianchi ME. The high mobility group (HMG) boxes of the nuclear protein HMG1 induce chemotaxis and cytoskeleton reorganization in rat smooth muscle cells. J Cell Biol. 2001; 152:1197-1206.

41. Prasad S, Thakur MK. Distribution of high mobility group proteins in different tissues of rats during aging. Biochem Int. 1990; 20:687-695.

42. Cabart P, Kalousek I, Jandova D, Hrkal Z. Differential expression of nuclear HMG1, HMG2 proteins and H1(zero) histone in various blood cells. Cell Biochem Funct. 1995; $13: 125-133$

43. Sun S, Zhang W, Cui Z, Chen Q, Xie P, Zhou C, Liu B, Peng X, Zhang Y. High mobility group box-1 and its clinical value in breast cancer. Onco Targets Ther. 2015; 8:413-419.

44. Lee H, Shin N, Song M, Kang UB, Yeom J, Lee C, Ahn YH, Yoo JS, Paik YK, Kim H. Analysis of nuclear high mobility group box 1 (HMGB1)-binding proteins in colon cancer cells: clustering with proteins involved in secretion and extranuclear function. J Proteome Res. 2010; 9:4661-4670.

45. Lotze MT, Tracey KJ. High-mobility group box 1 protein (HMGB1): nuclear weapon in the immune arsenal. Nat Rev Immunol. 2005; 5:331-342.

46. Andersson U, Harris HE. The role of HMGB1 in the pathogenesis of rheumatic disease. Biochim Biophys Acta. 2010; 1799:141-148.

47. Kawane K, Ohtani M, Miwa K, Kizawa T, Kanbara Y, Yoshioka Y, Yoshikawa H, Nagata S. Chronic polyarthritis caused by mammalian DNA that escapes from degradation in macrophages. Nature. 2006; 443:998-1002.

48. Jiang W, Bell CW, Pisetsky DS. The relationship between apoptosis and high-mobility group protein 1 release from murine macrophages stimulated with lipopolysaccharide or polyinosinic-polycytidylic acid. J Immunol. 2007; 178:6495-6503.
49. Stros M. HMGB proteins: interactions with DNA and chromatin. Biochim Biophys Acta. 2010; 1799:101-113.

50. Assenberg R, Webb M, Connolly E, Stott K, Watson M, Hobbs J, Thomas JO. A critical role in structure-specific DNA binding for the acetylatable lysine residues in HMGB1. Biochem J. 2008; 411:553-561.

51. Elenkov I, Pelovsky P, Ugrinova I, Takahashi M, Pasheva E. The DNA binding and bending activities of truncated tailless HMGB1 protein are differentially affected by Lys- 2 and Lys-81 residues and their acetylation. Int J Biol Sci. 2011; 7:691-699.

52. Ito I, Fukazawa J, Yoshida M. Post-translational methylation of high mobility group box 1 (HMGB1) causes its cytoplasmic localization in neutrophils. J Biol Chem. 2007; 282:16336-16344.

53. Webb M, Thomas JO. Structure-specific binding of the two tandem HMG boxes of HMG1 to four-way junction DNA is mediated by the A domain. J Mol Biol. 1999; 294:373-387.

54. Kang R, Zhang Q, Zeh HJ 3rd, Lotze MT, Tang D. HMGB1 in cancer: good, bad, or both? Clin Cancer Res. 2013; 19:4046-4057.

55. Pil PM, Chow CS, Lippard SJ. High-mobility-group 1 protein mediates DNA bending as determined by ring closures. Proc Natl Acad Sci U S A. 1993; 90:9465-9469.

56. Lange SS, Vasquez KM. HMGB1: the jack-of-all-trades protein is a master dna repair mechanic. Mol Carcinogen. 2009; 48:571-580.

57. Lange SS, Mitchell DL, Vasquez KM. High mobility group protein B1 enhances DNA repair and chromatin modification after DNA damage. Proc Natl Acad Sci U S A. 2008; 105:10320-10325.

58. Yuan FH, Lu LY, Guo SL, Wang CM, Li GM. Evidence for involvement of HMGB1 protein in human DNA mismatch repair. J Biol Chem. 2004; 279:20935-20940.

59. Prasad R, Liu Y, Deterding LJ, Poltoratsky VP, Kedar PS, Horton JK, Kanno SI, Asagoshi K, Hou EW, Khodyreva SN, Lavrik OI, Tomer KB, Yasui A, Wilson SH. HMGB1 is a cofactor in mammalian base excision repair. Mol Cell. 2007; 27:829-841.

60. Weterings E, Chen DJ. The endless tale of non-homologous end-joining. Cell Res. 2008; 18:114-124.

61. Lange SS, Reddy MC, Vasquez KM. Human HMGB1 directly facilitates interactions between nucleotide excision repair proteins on triplex-directed psoralen interstrand crosslinks. DNA Repair. 2009; 8:865-872.

62. Farid RS, Bianchi ME, Falciola L, Engelsberg BN, Billings PC. Differential binding of HMG1, HMG2, and a single HMG box to cisplatin-damaged DNA. Toxicol Appl Pharmacol. 1996; 141:532-539.

63. Pil PM, Lippard SJ. Specific binding of chromosomal protein HMG1 to DNA damaged by the anticancer drug cisplatin. Science. 1992; 256:234-237. 
64. Zamble DB, Mu D, Reardon JT, Sancar A, Lippard SJ. Repair of cisplatin--DNA adducts by the mammalian excision nuclease. Biochemistry. 1996; 35:10004-10013.

65. Yumoto Y, Shirakawa H, Yoshida M, Suwa A, Watanabe F, Teraoka H. High mobility group proteins 1 and 2 can function as DNA-binding regulatory components for DNA-dependent protein kinase in vitro. J Biochem. 1998; 124:519-527.

66. Lai KK, Chan KT, Choi MY, Wang HK, Fung EY, Lam HY, Tan W, Tung LN, Tong DK, Sun RW, Lee NP, Law S. 14-33 sigma confers cisplatin resistance in esophageal squamous cell carcinoma cells via regulating DNA repair molecules. Tumour Biol. 2016; 37:2127-2136.

67. Rowell JP, Simpson KL, Stott K, Watson M, Thomas JO. HMGB1-facilitated p53 DNA binding occurs via HMGBox/p53 transactivation domain interaction, regulated by the acidic tail. Structure. 2012; 20:2014-2024.

68. Stros M, Ozaki T, Bacikova A, Kageyama H, Nakagawara A. HMGB1 and HMGB2 cell-specifically down-regulate the p53-and p73-dependent sequence-specific transactivation from the human Bax gene promoter. J Biol Chem. 2002; 277:7157-7164.

69. Joshi SR, Sarpong YC, Peterson RC, Scovell WM. Nucleosome dynamics: HMGB1 relaxes canonical nucleosome structure to facilitate estrogen receptor binding. Nucleic Acids Res. 2012; 40:10161-10171.

70. Song MJ, Hwang SM, Wong W, Round J, Martinez-Guzman D, Turpaz Y, Liang J, Wong B, Johnson RC, Carey M, Sun R. The DNA architectural protein HMGB1 facilitates RTAmediated viral gene expression in gamma-2 herpesviruses. J Virol. 2004; 78:12940-12950.

71. Jiao Y, Wang HC, Fan SJ. Growth suppression and radiosensitivity increase by HMGB1 in breast cancer. Acta Pharmacol Sin. 2007; 28:1957-1967.

72. Agresti A, Lupo R, Bianchi ME, Muller S. HMGB1 interacts differentially with members of the Rel family of transcription factors. Biochem Bioph Res Co. 2003; 302:421-426.

73. Jayaraman L, Moorthy NC, Murthy KGK, Manley JL, Bustin M, Prives C. High mobility group protein-1 (HMG-1) is a unique activator of p53. Gene Dev. 1998; 12:462-472.

74. Mitsouras K, Wong B, Arayata C, Johnson RC, Carey M. The DNA architectural protein HMGB1 displays two distinct modes of action that promote enhanceosome assembly. Mol Cell Biol. 2002; 22:4390-4401.

75. Ge H, Roeder RG. The high mobility group protein HMG1 can reversibly inhibit class II gene transcription by interaction with the TATA-binding protein. J Biol Chem. 1994; 269:17136-17140

76. Polanska E, Dobsakova Z, Dvorackova M, Fajkus J, Stros M. HMGB1 gene knockout in mouse embryonic fibroblasts results in reduced telomerase activity and telomere dysfunction. Chromosoma. 2012; 121:419-431.
77. Qiang W, Wu Q, Zhou F, Xie C, Wu C, Zhou Y. Suppression of telomere-binding protein TPP1 resulted in telomere dysfunction and enhanced radiation sensitivity in telomerase-negative osteosarcoma cell line. Biochem Biophys Res Commun. 2014; 445:363-368.

78. Ke SB, Zhou FX, Yang H, Wei YH, Gong J, Mei ZJ, Wu L, Yu HJ, Zhou YF. Downregulation of high mobility group box 1 modulates telomere homeostasis and increases the radiosensitivity of human breast cancer cells. Int J Oncol. 2015; 46:1051-1058.

79. Zhao M, Yang M, Yang L, Yu Y, Xie M, Zhu S, Kang R, Tang D, Jiang Z, Yuan W, Wu X, Cao L. HMGB1 regulates autophagy through increasing transcriptional activities of JNK and ERK in human myeloid leukemia cells. BMB Rep. 2011; 44:601-606.

80. Livesey KM, Kang R, Vernon P, Buchser W, Loughran P, Watkins SC, Zhang L, Manfredi JJ, Zeh HJ 3rd, Li L, Lotze MT, Tang D. p53/HMGB1 complexes regulate autophagy and apoptosis. Cancer Res. 2012; 72:1996-2005.

81. Livesey KM, Kang R, Zeh HJ, Lotze MT, Tang DL. Direct molecular interactions between HMGB1 and TP53 in colorectal cancer. Autophagy. 2012; 8:846-848.

82. $\mathrm{Yu}$ M. Generation, function and diagnostic value of mitochondrial DNA copy number alterations in human cancers. Life Sci. 2011; 89:65-71.

83. Liu Y, Yan W, Tohme S, Chen M, Fu Y, Tian D, Lotze M, Tang D, Tsung A. Hypoxia induced HMGB1 and mitochondrial DNA interactions mediate tumor growth in hepatocellular carcinoma through Toll-like receptor 9. J Hepatol. 2015; 63:114-121.

84. Nickel W. Unconventional secretory routes: direct protein export across the plasma membrane of mammalian cells. Traffic. 2005; 6:607-614.

85. Fuentes E, Rojas A, Palomo I. Role of multiligand/RAGE axis in platelet activation. Thromb Res. 2014; 133:308-314.

86. Hanspal M, Hanspal JS. The association of erythroblasts with macrophages promotes erythroid proliferation and maturation: a $30-\mathrm{kD}$ heparin-binding protein is involved in this contact. Blood. 1994; 84:3494-3504.

87. Ciucci A, Gabriele I, Percario ZA, Affabris E, Colizzi V, Mancino G. HMGB1 and cord blood: its role as immunoadjuvant factor in innate immunity. PLoS One. 2011; 6:e23766.

88. Jube S, Rivera ZS, Bianchi ME, Powers A, Wang E, Pagano I, Pass HI, Gaudino G, Carbone M, Yang H. Cancer cell secretion of the DAMP protein HMGB1 supports progression in malignant mesothelioma. Cancer Res. 2012; 72:3290-3301.

89. Feng X, Hao J, Liu Q, Yang L, Lv X, Zhang Y, Xing L, $\mathrm{Xu}$ N, Liu S. HMGB1 mediates IFN-gamma-induced cell proliferation in MMC cells through regulation of cyclin D1/ CDK4/p16 pathway. J Cell Biochem. 2012; 113:2009-2019.

90. Kang R, Tang D, Schapiro NE, Loux T, Livesey KM, Billiar TR, Wang H, Van Houten B, Lotze MT, Zeh HJ. The HMGB1/RAGE inflammatory pathway promotes pancreatic 
tumor growth by regulating mitochondrial bioenergetics. Oncogene. 2014; 33:567-577.

91. Chitanuwat A, Laosrisin N, Dhanesuan N. Role of HMGB1 in proliferation and migration of human gingival and periodontal ligament fibroblasts. J Oral Sci. 2013; 55:45-50.

92. Taguchi A, Blood DC, del Toro G, Canet A, Lee DC, Qu W, Tanji N, Lu Y, Lalla E, Fu CF, Hofmann MA, Kislinger T, Ingram $\mathrm{M}$, et al. Blockade of RAGE-amphoterin signalling suppresses tumour growth and metastases. Nature. 2000; 405:354-360.

93. Yan W, Chang Y, Liang X, Cardinal JS, Huang H, Thorne SH, Monga SP, Geller DA, Lotze MT, Tsung A. Highmobility group box 1 activates caspase- 1 and promotes hepatocellular carcinoma invasiveness and metastases. Hepatology. 2012; 55:1863-1875.

94. Zuo Z, Che X, Wang Y, Li B, Li J, Dai W, Lin CP, Huang C. High mobility group Box-1 inhibits cancer cell motility and metastasis by suppressing activation of transcription factor CREB and nWASP expression. Oncotarget. 2014; 5:74587470. doi: 10.18632/oncotarget.2150.

95. van Beijnum JR, Dings RP, van der Linden E, Zwaans BM, Ramaekers FC, Mayo KH, Griffioen AW. Gene expression of tumor angiogenesis dissected: specific targeting of colon cancer angiogenic vasculature. Blood. 2006; 108:2339-2348.

96. van Beijnum JR, Nowak-Sliwinska P, van den Boezem E, Hautvast P, Buurman WA, Griffioen AW. Tumor angiogenesis is enforced by autocrine regulation of highmobility group box 1. Oncogene. 2013; 32:363-374.

97. Sasahira T, Kirita T, Bhawal UK, Ikeda M, Nagasawa A, Yamamoto K, Kuniyasu H. The expression of receptor for advanced glycation end products is associated with angiogenesis in human oral squamous cell carcinoma. Virchows Arch. 2007; 450:287-295.

98. Zhang CL, Shu MG, Qi HW, Li LW. Inhibition of tumor angiogenesis by HMGB1 A box peptide. Med Hypotheses. 2008; 70:343-345.

99. Urbich C, Dimmeler S. Endothelial progenitor cells: characterization and role in vascular biology. Circ Res. 2004; 95:343-353.

100. Palumbo R, Sampaolesi M, De Marchis F, Tonlorenzi R, Colombetti S, Mondino A, Cossu G, Bianchi ME. Extracellular HMGB1, a signal of tissue damage, induces mesoangioblast migration and proliferation. J Cell Biol. 2004; 164:441-449.

101. Igney FH, Krammer PH. Death and anti-death: tumour resistance to apoptosis. Nat Rev Cancer. 2002; 2:277-288.

102. Liu K, Huang J, Xie M, Yu Y, Zhu S, Kang R, Cao LZ, Tang DL, Duan XC. MIR34A regulates autophagy and apoptosis by targeting HMGB1 in the retinoblastoma cell. Autophagy. 2014; 10:442-452.

103. Zhan ZZ, Li Q, Wu P, Ye Y, Tseng HY, Zhang LJ, Zhang XD. Autophagy-mediated HMGB1 release antagonizes apoptosis of gastric cancer cells induced by vincristine via transcriptional regulation of Mcl-1. Autophagy. 2012; 8:109-121.

104. Gdynia G, Keith M, Kopitz J, Bergmann M, Fassl A, Weber AN, George J, Kees T, Zentgraf HW, Wiestler OD, Schirmacher P, Roth W. Danger signaling protein HMGB1 induces a distinct form of cell death accompanied by formation of giant mitochondria. Cancer Res. 2010; 70:8558-8568.

105. Tadie JM, Bae HB, Deshane JS, Bell CP, Lazarowski ER, Chaplin DD, Thannickal VJ, Abraham E, Zmijewski JW. Toll-like receptor 4 engagement inhibits adenosine 5'-monophosphate-activated protein kinase activation through a high mobility group box 1 protein-dependent mechanism. Mol Med. 2012; 18:659-668.

106. Weng H, Deng Y, Xie Y, Liu H, Gong F. Expression and significance of HMGB1, TLR4 and NF-kappaB p65 in human epidermal tumors. Bmc Cancer. 2013; 13:311.

107. Yan HX, Wu HP, Zhang HL, Ashton C, Tong C, Wu H, Qian QJ, Wang HY, Ying QL. p53 promotes inflammationassociated hepatocarcinogenesis by inducing HMGB1 release. J Hepatol. 2013; 59:762-768.

108. Yang H, Tracey KJ. Targeting HMGB1 in inflammation. Biochim Biophys Acta. 2010; 1799:149-156.

109. Campana L, Bosurgi L, Rovere-Querini P. HMGB1: a twoheaded signal regulating tumor progression and immunity. Curr Opin Immunol. 2008; 20:518-523.

110. Krysko DV, Garg AD, Kaczmarek A, Krysko O, Agostinis P, Vandenabeele P. Immunogenic cell death and DAMPs in cancer therapy. Nat Rev Cancer. 2012; 12:860-875.

111. Zhao T, Ren H, Wang X, Liu P, Yan F, Jiang W, Li Y, Li J, Gribben JG, Jia L, Hao J. Rituximab-induced HMGB1 release is associated with inhibition of STAT3 activity in human diffuse large B-cell lymphoma. Oncotarget. 2015; 6:27816-27831. doi: 10.18632/oncotarget.4816.

112. Kazama H, Ricci JE, Herndon JM, Hoppe G, Green DR, Ferguson TA. Induction of immunological tolerance by apoptotic cells requires caspase-dependent oxidation of high-mobility group box-1 protein. Immunity. 2008; 29:21-32.

113. Luo Y, Ohmori H, Fujii K, Moriwaka Y, Sasahira T, Kurihara M, Tatsumoto N, Sasaki T, Yamashita Y, Kuniyasu H. HMGB1 attenuates anti-metastatic defence of the liver in colorectal cancer. Eur J Cancer. 2010; 46:791-799.

114. Amornsupak K, Insawang T, Thuwajit P, O-Charoenrat P, Eccles SA, Thuwajit C. Cancer-associated fibroblasts induce high mobility group box 1 and contribute to resistance to doxorubicin in breast cancer cells. BMC Cancer. 2014; 14:955.

115. Li Q, Li J, Wen T, Zeng W, Peng C, Yan S, Tan J, Yang K, Liu S, Guo A, Zhang C, Su J, Jiang M, et al. Overexpression of HMGB1 in melanoma predicts patient survival and suppression of HMGB1 induces cell cycle arrest and senescence in association with p21 (Wafl/ Cip1) up-regulation via a p53-independent, Sp1-dependent 
pathway. Oncotarget. 2014; 5:6387-6403. doi: 10.18632/ oncotarget. 2201.

116. Mollica L, De Marchis F, Spitaleri A, Dallacosta C, Pennacchini D, Zamai M, Agresti A, Trisciuoglio L, Musco G, Bianchi ME. Glycyrrhizin binds to high-mobility group box 1 protein and inhibits its cytokine activities. Chem Biol. 2007; 14:431-441.

117. Ogiku M, Kono H, Hara M, Tsuchiya M, Fujii H. Glycyrrhizin prevents liver injury by inhibition of high-mobility group box 1 production by Kupffer cells after ischemia-reperfusion in rats. J Pharmacol Exp Ther. 2011; 339:93-98.

118. Smolarczyk R, Cichon T, Matuszczak S, Mitrus I, Lesiak M, Kobusinska M, Kamysz W, Jarosz M, Sieron A, Szala $\mathrm{S}$. The role of glycyrrhizin, an inhibitor of hmgb1 protein, in anticancer therapy. Arch Immunol Ther Ex. 2012; 60:391-399.

119. Ohmori H, Luo Y, Kuniyasu H. Non-histone nuclear factor HMGB1 as a therapeutic target in colorectal cancer. Expert Opin Ther Targets. 2011; 15:183-193.

120. Lee H, Song M, Shin N, Shin CH, Min BS, Kim HS, Yoo JS, Kim H. Diagnostic significance of serum HMGB1 in colorectal carcinomas. PLos One. 2012; 7: e34318.

121. Jube S, Rivera ZS, Bianchi ME, Powers A, Wang E, Pagano I, Pass HI, Gaudino G, Carbone M, Yang HN. Cancer cell secretion of the DAMP protein HMGB1 supports progression in malignant mesothelioma. Cancer Res. 2012; 72:3290-3301.

122. Pellegrini L, Xue J, Larson D, Pastorino S, Jube S, Forest KH, Saad-Jube ZS, Napolitano A, Pagano I, Negi VS, Bianchi ME, Morris P, Pass HI, et al. HMGB1 targeting by ethyl pyruvate suppresses malignant phenotype of human mesothelioma. Oncotarget. 2017; 8:22649-22661. doi: 10.18632/oncotarget.15152.

123. Tang D, Kang R, Xiao W, Zhang H, Lotze MT, Wang H, Xiao X. Quercetin prevents LPS-induced high-mobility group box 1 release and proinflammatory function. Am J Respir Cell Mol Biol. 2009; 41:651-660.

124. Pang H, Huang T, Song J, Li D, Zhao Y, Ma X. Inhibiting HMGB1 with glycyrrhizic acid protects brain injury after DAI via Its anti-inflammatory effect. Mediators Inflamm. 2016; 2016:4569521.

125. Ulloa $\mathrm{L}$. The vagus nerve and the nicotinic anti-inflammatory pathway. Nat Rev Drug Discov. 2005; 4:673-684.

126. Calogero S, Grassi F, Aguzzi A, Voigtlander T, Ferrier P, Ferrari S, Bianchi ME. The lack of chromosomal protein Hmg1 does not disrupt cell growth but causes lethal hypoglycaemia in newborn mice. Nat Genet. 1999; 22:276-280

127. Penumutchu SR, Chou RH, Yu C. Structural insights into calcium-bound S100P and the V domain of the RAGE complex. PLoS One. 2014; 9:e103947.
128. Tang D, Loze MT, Zeh HJ, Kang R. The redox protein HMGB1 regulates cell death and survival in cancer treatment. Autophagy. 2010; 6:1181-1183.

129. Ulloa L, Messmer D. High-mobility group box 1 (HMGB1) protein: friend and foe. Cytokine Growth Factor Rev. 2006; $17: 189-201$

130. Xiao JB, Ding Y, Huang J, Li QS, Liu Y, Ni W, Zhang YQ, Zhu YF, Chen LH, Chen B. The association of HMGB1 gene with the prognosis of HCC. Plos Lne. 2014; 9:e89097.

131. Zhang J, Kou YB, Zhu JS, Chen WX, Li S. Knockdown of HMGB1 inhibits growth and invasion of gastric cancer cells through the NF- $\mathrm{KB}$ pathway in vitro and in vivo. Int J Oncol. 2014; 44:1268-1276.

132. Suren D, Yildirim M, Demirpence O, Kaya V, Alikanoglu AS, Bulbuller N, Yildiz M, Sezer C. The role of high mobility group box 1 (HMGB1) in colorectal cancer. Med Sci Monit. 2014; 20:530-537.

133. Takeda T, Izumi H, Kitada S, Uramoto H, Tasaki T, Zhi L, Guo X, Kawatsu Y, Kimura T, Horie S, Nabeshima A, Noguchi H, Wang KY, et al. The combination of a nuclear HMGB1-positive and HMGB2-negative expression is potentially associated with a shortened survival in patients with pancreatic ductal adenocarcinoma. Tumour Biol. 2014; 35:10555-10569.

134. Lee HJ, Kim JY, Song IH, Park IA, Yu JH, Ahn JH, Gong G. High mobility group B1 and N1 (HMGB1 and HMGN1) are associated with tumor-infiltrating lymphocytes in HER2positive breast cancers. Virchows Arch. 2015; 467:701-709.

135. Pang X, Zhang Y, Wei H, Zhang J, Luo Q, Huang C, Zhang S. Expression and effects of high-mobility group box 1 in cervical cancer. Int J Mol Sci. 2014; 15:8699-8712.

136. Wang XJ, Zhou SL, Fu XD, Zhang YY, Liang B, Shou JX, Wang JY, Ma J. Clinical and prognostic significance of high-mobility group box-1 in human gliomas. Exp Ther Med. 2015; 9:513-518.

137. Moser B, Janik S, Schiefer AI, Mullauer L, Bekos C, Scharrer A, Mildner M, Renyi-Vamos F, Klepetko W, Ankersmit HJ. Expression of RAGE and HMGB1 in thymic epithelial tumors, thymic hyperplasia and regular thymic morphology. PLoS One. 2014; 9:e94118.

138. Meyer A, Staratschek-Jox A, Springwald A, Wenk H, Wolf J, Wickenhauser C, Bullerdiek J. Non-Hodgkin lymphoma expressing high levels of the dangersignalling protein HMGB1. Leuk Lymphoma. 2008; 49:1184-1189. 